Fanum

Sociológico

\section{Forum Sociológico}

Série II

$18 \mid 2008$

Explorando os interstícios urbanos

\title{
Imagens de um destino turístico: o caso de Cabo Verde
}

Maria do Carmo Lorena Santos

\section{(2) OpenEdition \\ 1 Journals}

\section{Edição electrónica}

URL: https://journals.openedition.org/sociologico/285

DOI: 10.4000/sociologico.285

ISSN: 2182-7427

\section{Editora}

CICS.NOVA - Centro Interdisciplinar de Ciências Sociais da Universidade Nova de Lisboa

\section{Edição impressa}

Data de publição: 1 junho 2008

Paginação: 69-77

ISSN: 0872-8380

\section{Refêrencia eletrónica}

Maria do Carmo Lorena Santos, «Imagens de um destino turístico: o caso de Cabo Verde», Forum

Sociológico [Online], 18 | 2008, posto online no dia 03 dezembro 2012, consultado o 29 março 2022

URL: http://journals.openedition.org/sociologico/285 ; DOI: https://doi.org/10.4000/sociologico.285

Este documento foi criado de forma automática no dia 29 março 2022.

(c) CICS.NOVA 


\title{
Imagens de um destino turístico: o caso de Cabo Verde
}

\author{
Maria do Carmo Lorena Santos
}

\section{Introdução $^{1}$}

1 Na literatura sócio-antropológica sobre turismo este é definido, regra geral, como uma prática social que envolve o corte com rotinas estabelecidas do dia-a-dia, representando assim uma ruptura no quotidiano cujo propósito é, antes de mais, experienciar algo de extraordinário (Smith, 1989; Urry, 1990). o turismo insere-se no campo mais vasto do lazer, na sua oposição definidora com o trabalho. Mas, para além das diferentes ocupações dos actores envolvidos, existe também uma diferença cultural que supostamente seria o catalisador dessa experiência extraordinária. Ou seja, as diferentes culturas e diferentes ocupações definem, à partida, aquilo que caracteriza o turismo (Cohen, 1979; Nash, 1981).

2 Para certos autores, o turista é mesmo motivado pela necessidade de experienciar autenticidade, não obstante esta poder ser uma busca frustrada devido à encenação dos espaços turísticos (MacCannell, 1989). Muitas vezes, as comunidades visitadas transformam-se em palcos de "encenações" turísticas com o único propósito de satisfazer as imagens estereotipadas que os turistas transportam nas suas bagagens (Crick, 1989; Cohen, 1993).

3 Face à vontade de experienciar um Outro diferente, o turismo utiliza práticas de significação institucionais para promover uma apresentação muitas vezes redutora dos lugares e das pessoas enquanto mero espectáculo de entretenimento. Essas práticas consubstanciam-se nas imagens da publicidade turística, que para muitos não são mais do que mitos sobre os demais ancorados na atracção do turista pela novidade e pela diferença.

4 Um dos temas recorrentes na literatura prende-se com a crítica à mercadorização $\mathrm{e}$ exotização do Outro, das quais os países do chamado Terceiro Mundo são alvos particularmente fáceis, sendo as suas populações e culturas muitas vezes vistas como 
estáticas e cristalizadas no tempo. Estes destinos são vulgarmente descritos pela indústria turística como paraísos inexplorados, exóticos, autênticos, primitivos, coloridos $^{2}$. O uso selectivo de imagens para vender estes temas e criar um destino imaginário, irreal ou "mítico" caracteriza o discurso promocional no qual estas e outras distorções semelhantes persistem presumivelmente para compensar a pobreza existente para lá do olhar turístico, que é um dos "silêncios significativos" que há que manter (Cohen, 1993; Echtner, 2002; Echtner \& Prasad, 2003).

5 Esta tensão entre a forma como os destinos são apresentados aos turistas e a sua real complexidade convoca a reflexão sobre os mecanismos subjacentes que produzem e reproduzem esta discrepância e sobre as ideologias e interesses em jogo na criação das imagens turísticas (Cohen, 1993).

6 A teoria do pós-colonialismo aparece frequentemente como um suporte analítico nos estudos das imagens turísticas. A linguagem promocional é assim tomada como uma das muitas formas de representação do Terceiro Mundo que, ainda que de modo subtil, serve para manter e reforçar a ideologia colonial e as estruturas e relações de poder que esta fomenta, o que ocorre através da criação de oposições binárias como Primeiro Mundo/Terceiro Mundo, desenvolvido/subdesenvolvido, normal/

/exótico, que reificam as fronteiras dicotómicas entre uns e outros. Assim, é defendido que os estereótipos ocidentais e coloniais são replicados e reforçados através da linguagem do turismo, em particular face aos destinos outrora colonizados (Echtner, 2002; Echtner \& Prasad, 2003). Para muitos, a motivação turística decorre de um alegado desejo da sociedade moderna de experienciar culturas "pré-modernas" e de um certo fascínio pelo passado. Assim, a História torna-se uma mercadoria e a autenticidade é vista como estando noutros tempos e lugares, supostamente mais puros e tradicionais (MacCannell, 1989; Urry, 1990; Sharpley, 2008).

\section{Olhar turístico, imagem de destino e discurso promocional}

7 Para Urry (1990), o olhar turístico é construído através da diferença, em relação ao seu oposto, a formas não-turísticas de experiência social. O olhar turístico não é uma actividade meramente individual, é socialmente organizado, na medida em que há profissionais que ajudam a construir e desenvolver o nosso olhar enquanto turistas, através dos guias turísticos, da publicidade, dos media ou da literatura de viagens. A atracção turística envolve, portanto, processos complexos de produção, em que olhares turísticos são gerados e sustentados. As pessoas têm de aprender como e para onde olhar.

8 A motivação básica para viajar reside na vontade de olhar para paisagens, sítios ou pessoas diferentes, que estão fora da normalidade e da rotina do dia-a-dia. Mas a motivação está também relacionada com a antecipação da viagem e este é um elemento fundamental da experiência turística. Neste sentido, os lugares são escolhidos porque há uma antecipação de prazeres intensos (Urry, 1990; Sharpley, 2008).

Uma das maiores motivações da viagem é, sem dúvida, a imagem do destino, sendo esta uma percepção mental que se tem de um dado sítio e não apenas uma representação visual do lugar (Garrod, 2008). Todavia, o consumo turístico é primeiramente e principalmente visual (Jenkins, 2003) e na literatura especializada é dada particular 
ênfase às representações visuais dos destinos e à centralidade que estas desempenham nas percepções que as pessoas têm dos lugares turísticos.

10 Mas as imagens turísticas têm sido também analisadas para lá do seu lado pictórico, sendo encaradas como narrativas que devem ser contextualizadas dentro de discursos políticos, culturais e sociais mais amplos. Estas interpretações, partilhadas por vários autores, partem de uma perspectiva que encara as imagens dos destinos como "textos" que representam o mundo e que têm subjacentes determinados significados e valores culturais. Assim, as imagens turísticas, enquanto textos e reservatórios culturais que se inserem na ideologia dominante de uma sociedade, reflectem e moldam discursos particulares sobre sítios e identidades. Muitas vezes, certos aspectos das comunidades locais são essencializados, dados os papéis representados e relegados para os indivíduos nas ilustrações pictóricas dos destinos. Como tal, a imagética promocional é criticada por uma não inclusão que reforça estereótipos. As mensagens promocionais não são neutras nos conteúdos que comunicam e, ao divulgarem imagens idealizadas, circunscrevem os limites da experiência e direccionam o olhar turístico (Markwick, 2001; Jenkins, 2003; Pritchard \& Morgan, 2003; Aurindo, 2006; Arora, 2009).

11 A imagética da promoção turística apresenta cenários idílicos que alimentam o desejo dos turistas de escapar ao quotidiano. A complexidade da realidade dos destinos é então sujeita a uma profunda simplificação. Ainda que a imagem turística seja construída a partir de um referente real, são operacionalizadas estratégias de marketing que passam por privilegiar certos aspectos do destino em detrimento de outros, de forma a propiciar uma imagem de excepcionalidade. As imagens turísticas mascaram o mais desagradável e desta forma constroem selectivamente a realidade, convertendo-a num produto mais apelativo e sugestivo. O discurso turístico pauta-se pela selecção e descontextualização e apoia-se na exaltação e no exagero de certos traços do destino. Concomitantemente, ignora e silencia o que considera não dever fazer parte da atenção turística. Assim, mediante a informação que é incluída e excluída, a imagética turística providencia uma certa forma de ver o mundo.

12 Para Conceição (1998), o processo de transformação dos recursos turísticos em "objectos" de consumo passa quer por uma construção da imagem do destino enquanto espaço extraordinário, que se realiza através de um processo de mitificação do espaço turístico, quer por propostas de práticas e sinalização de locais de consumo turístico, definindo assim os contornos da experiência turística, o que corresponde a uma ritualização do espaço turístico. Segundo a autora, o discurso promocional é padronizado e caracteriza-se por uma forte carga adjectivante. Assim, expressões como fantástico, impressionante, "[...] revelam a tentativa de transformação dos destinos em realidades que transcendem o mundo quotidiano, tido como banal e desinteressante" (1998: 77). Além dos adjectivos e formas verbais (nomeadamente a utilização do superlativo sintético e analítico), a autora refere também a cor como um dos mecanismos mais comuns de sedução. Também Aurindo nota que "[...] a associação de um clima merecedor da deslocação materializa-se, ora em céus azuis e sem nuvens e em ambiências luminosas, ora em tons quentes e em representações pictóricas associadas ao elemento sol" (2006: 167). Segundo Conceição (1998), o discurso promocional pautase também por uma associação/conotação dos locais a valores como tradicional, histórico, típico, elementos que funcionam como uma certificação de autenticidade. Neste processo, o destino assume a forma de um local-mito. 
13 Markwick (2001), numa análise sobre as imagens dos postais turísticos de Malta, conclui também que estas veiculam significados simbólicos através dos temas que retratam. 0 autor agrupa as motivações turísticas em duas categorias. Na categoria Sunlust or the Search for the Exotic o autor integra os postais cuja representação "[...] evoca a visão romântica do Mediterrâneo, do seu clima e do seu ambiente, centrada nos mares azuis, nos céus brilhantes e nos areais [...]" (2001: 424) ${ }^{3}$. O autor nota que estes são componentes importantes na construção da diferença, sendo esta frequentemente apresentada em termos de cor e luz. São também comuns as referências a Malta enquanto ilha, particularmente em associação com o termo "paraíso". Por sua vez, a categoria Wanderlust or the Search for the Authentic inclui determinados elementos culturais que sugerem "autenticidade" e que são invariavelmente associados com o passado e a tradição. Assim, certos modos de vida como a pesca e antigos meios de transporte figuram nas imagens turísticas de forma a sugerir um modo de vida "autêntico". Outra referência notada pelo autor é a representação romântica da simplicidade das comunidades e da sua simpatia. "As caras sorridentes e hospitaleiras de 'locais alegres e amigáveis', por exemplo, são uma componente comum da imagética dos postais" (2001: 428). Para Markwick - numa abordagem que recupera a oposição goffmaniana de MacCannell entre uma front stage e uma back stage onde estaria a autenticidade - também as imagens do quotidiano conferem autenticidade à experiência turística na medida em que vincam um sentido de intimidade que apela ao suposto desejo de autenticidade do turista.

\section{A imagem turística de Cabo Verde ${ }^{4}$}

O turismo é a principal actividade económica de Cabo Verde, representando cerca de $20 \%$ do PIB, e é assumido pelo governo como o sector estratégico e prioritário enquanto factor de desenvolvimento do país. Além disso, a indústria turística do arquipélago encontra-se em franca expansão.

15 Cabo Verde, enquanto destino turístico, caracteriza-se por uma oferta fortemente vocacionada para o produto "sol e mar". Contudo, tal como outros destinos arquipelágicos, o país confronta-se hoje com a necessidade de alterar o esgotado modelo dos três Ss (sea, sun, sand) e diversificar os tipos de turismo. Assim, paulatinamente, formas alternativas de turismo vão ganhando espaço no mercado e assiste-se hoje em dia à emergência de novos tipos de turismo e de novas abordagens turísticas relativamente ao destino que é Cabo Verde. $O$ turismo balnear parece ceder algum espaço ao turismo rural e histórico/cultural, que começa a florescer no arquipélago.

16 Do ponto de vista da morfologia geográfica, Cabo Verde divide-se em duas zonas: as ilhas de orografia plana (Sal, Boavista e Maio) e as ilhas de orografia montanhosa (Brava, Fogo, Santiago, Santo Antão, São Vicente e São Nicolau). A esta variedade orográfica correspondem recursos e potencialidades turísticas distintas. A heterogeneidade que caracteriza o arquipélago e a tentativa de descentralização ao nível das ilhas e dos tipos de turismo reflecte-se claramente nas imagens e representações veiculadas pela promoção turística de Cabo Verde.

17 A imagem turística que é produzida e difundida sobre Cabo Verde assenta numa miríade de descrições que vão desde informações práticas sobre infra-estruturas ou oferta de actividades desportivas, passando pelo apelo da paisagem ou da cultura, até à 
apresentação de traços alegadamente únicos e singulares de Cabo Verde (hospitalidade, morabeza), ou gerais e comuns a outros destinos (paraíso, exótico).

18 A atractividade turística de Cabo Verde é vasta mas é possível agrupar os atractivos publicitados em categorias distintas, ainda que ramificáveis em subcategorias.

Na categoria "Clima e Natureza" identificámos elementos referentes à "Paisagem" e à "Fauna e Flora". No que concerne à primeira, encontramos apresentações como:

"A Praia de Santa Maria possui $8 \mathrm{~km}$ de extensão de areia branca, banhada por um mar azul-turquesa e águas límpidas e uma praia que convida a prolongados momentos de lazer em contacto com uma areia alva e fina e com um mar de primeira qualidade." (Soltrópico, Cabo Verde, Verão 2008, brochura, p. 5, www.soltropico.pt)

Apesar da persistência de imagens de praias com grandes areais e águas límpidas, a vegetação e a aridez, que contrastam entre elas, surgem também como que para lembrar que Cabo Verde é, de facto, um país de contrastes e como tal um destino com muitos potenciais.

Figura 1: Clima e Natureza - Paisagem - dunas

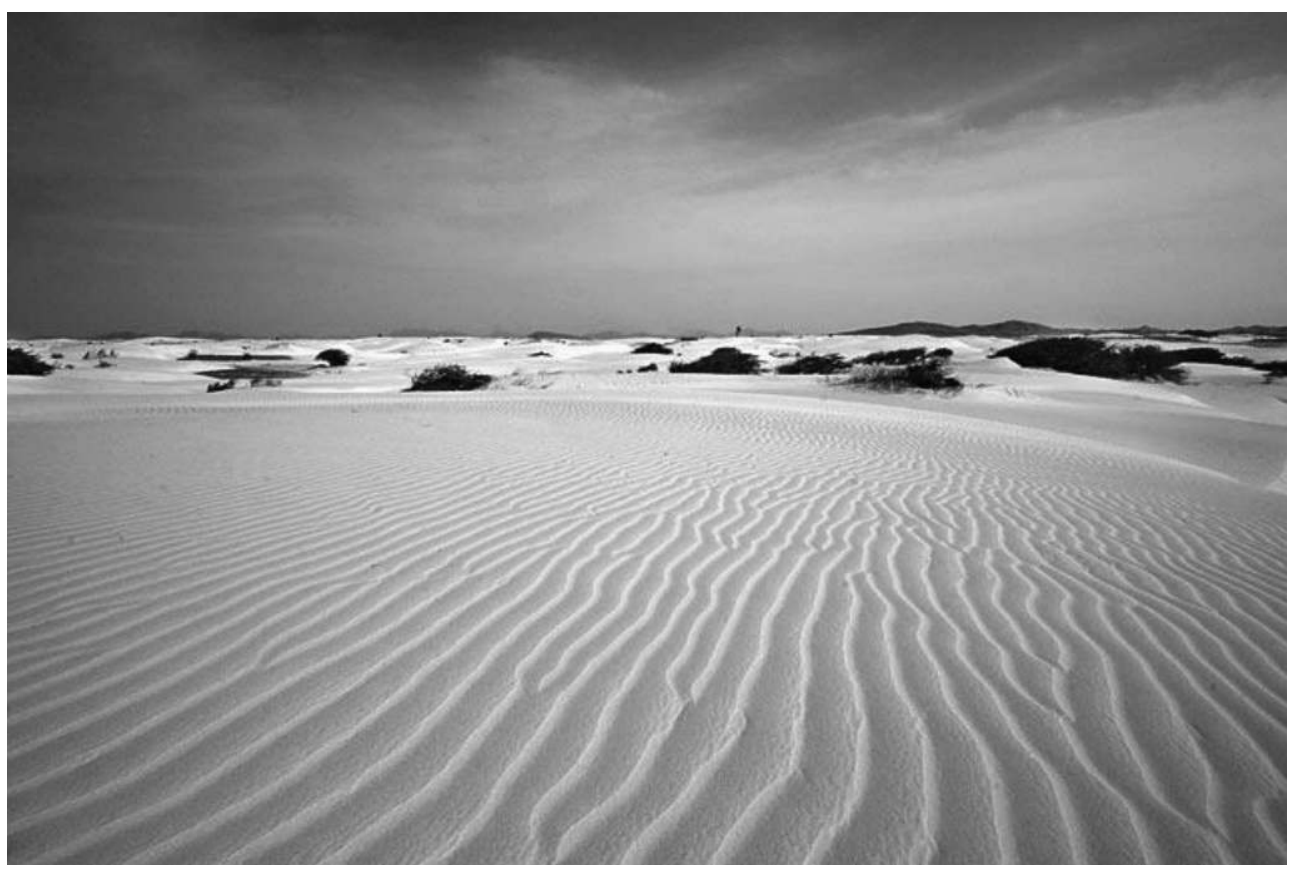

FONTE: WWW.CAPEVERDEEXPERIENCE.CO.UK 
Figura 2: Clima e Natureza - Paisagem - montanhas

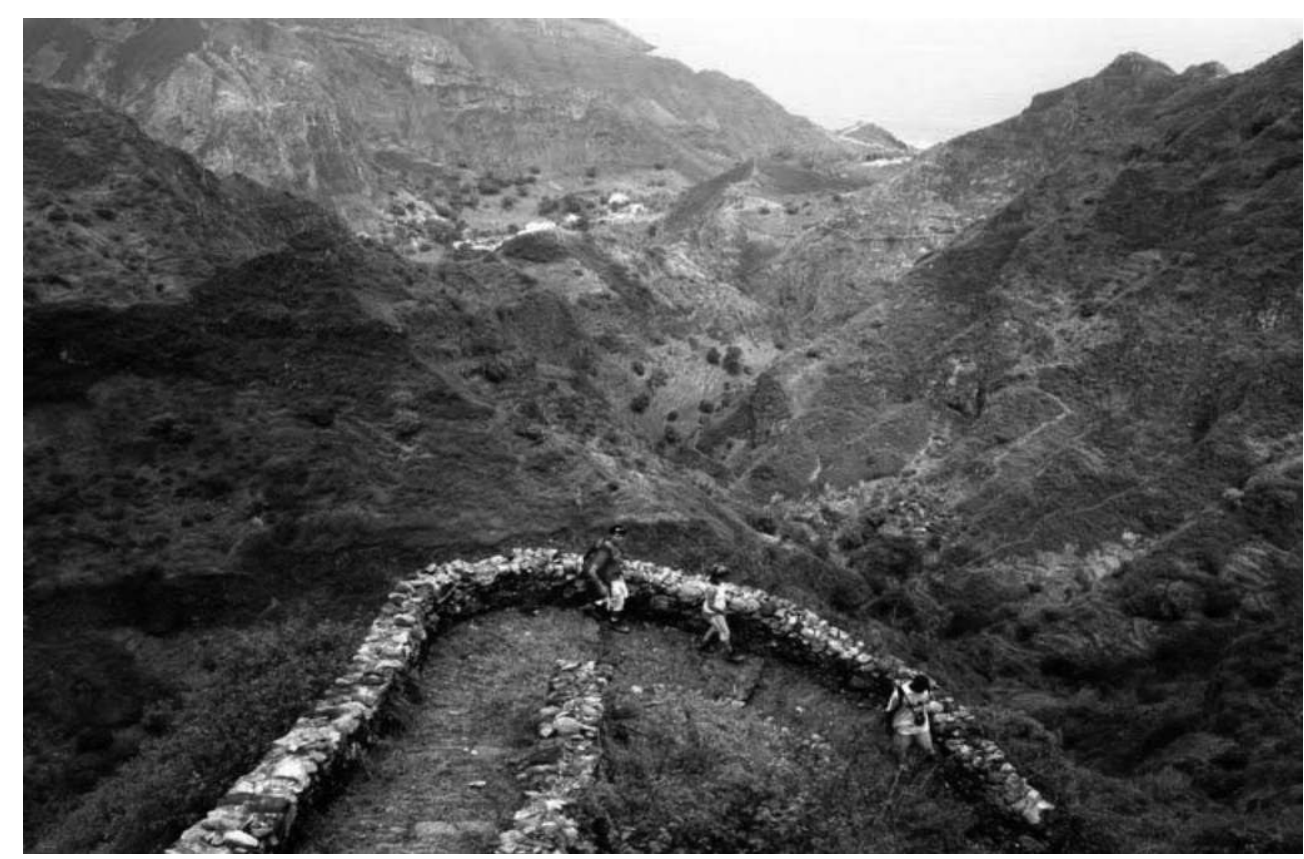

FONTE: WWW.CAVOQUINHO.COM

21 No que respeita à subcategoria "Fauna e Flora", mencionam-se repetidamente os fundos marinhos com os seus corais, cardumes de peixes, papaieiras, mangueiras, coqueiros, dragoeiros.

Na categoria "Cultura e Património" é possível identificar inúmeras subcategorias: "Música e Dança", "Gastronomia", "População e Costumes" e "História". Atentemos em alguns exemplos referentes a cada uma delas.

A subcategoria "Música e Dança" desdobra-se em referências várias: à morna, à coladeira, ao funaná, ao batuque, à tabanca. Esta musicalidade surge associada a um modo de "ser e estar", como podemos constatar da seguinte citação:

“A morna, expressão máxima da música nacional, nasceu aqui. Serenatas e tocatinas são uma componente primordial na vivência deste povo acolhedor e simpático, cheio de 'morabeza'. (Soltrópico, Cabo Verde, Ilhas da Morabeza, s/d., brochura, p. 28, www.soltropico.pt)

$\mathrm{Na}$ "Gastronomia", são referenciados a incontornável cachupa, os peixes e mariscos, a mandioca, o milho, a batata-doce, o grogue (aguardente de cana de açúcar) e o vinho do Fogo. Um exemplo do discurso narrativo:

“[...] é indispensável a todo e qualquer visitante degustar a excelente cozinha caboverdiana, na certeza de que os sabores locais são parte integrante e indispensável do conhecimento da cultura crioula de Cabo Verde." (Soltrópico, Cabo Verde, Ilhas da Morabeza, s/d., brochura, p. 28, www.soltropico.pt)

De sublinhar que todas estas descrições são vulgarmente acompanhadas por ilustrações. As referências relativas à "População e Costumes" são múltiplas e variadas. A morabeza e a hospitalidade da população são alguns dos atractivos amplamente divulgados:

"O caboverdiano, que se impregnou de várias culturas, é hospitaleiro e acolhedor"

(Anónimo, "O país da 'morabeza”", Cabo Verde, o país da "morabeza", 2005, separata da revista Viajar, p. 6) 
[...] um povo de sorriso sempre fácil, feliz com a vida serena que leva. (Caria, T., "Boavista 'nha cretcheu', A ilha mais bem guardada de Cabo Verde", Viajar, n.. 244, Dezembro 2008, revista, p. 10)

Figura 3: Cultura e Património - População e Costumes - crianças

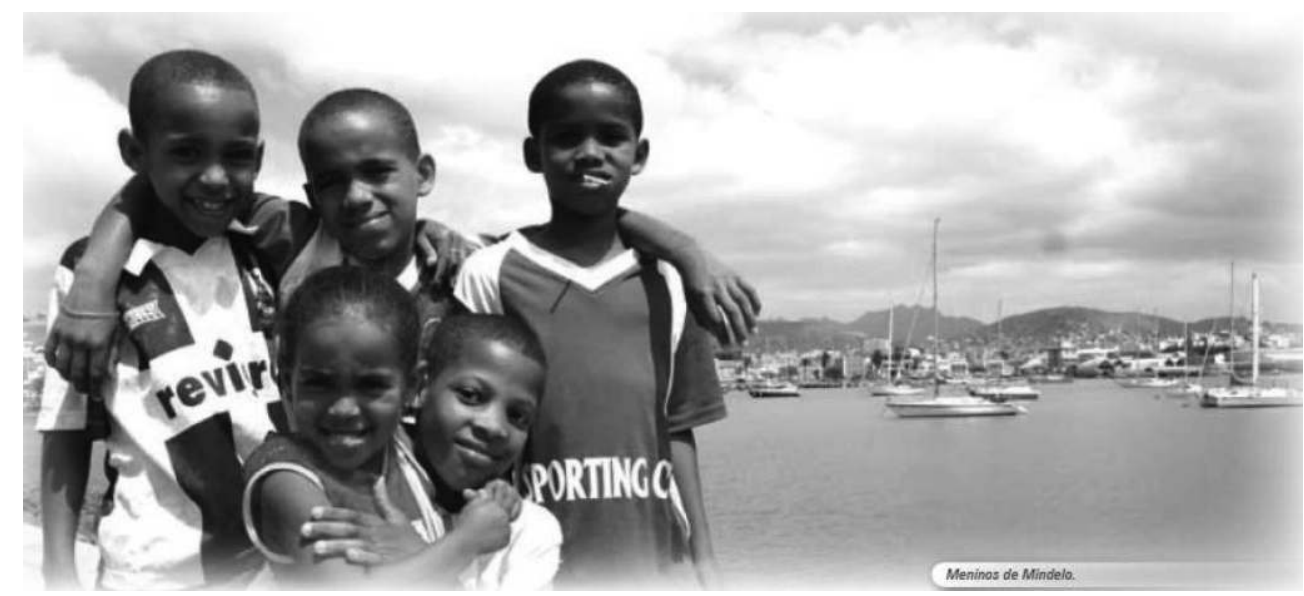

FONTE: WWW.SOLTROPICO.PT

Figura 4: Cultura e Património - População e Costumes - idosos

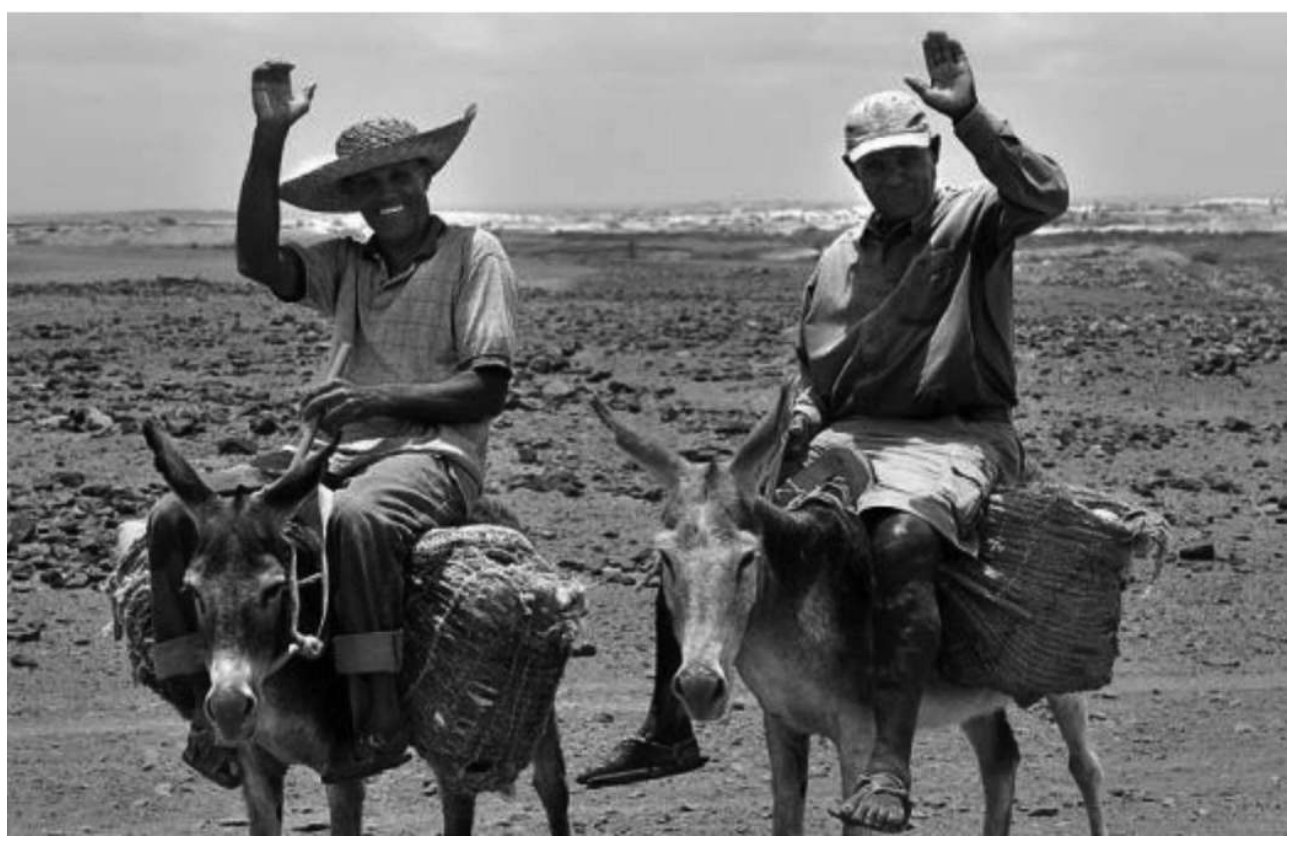

FONTE: WWW.CAPEVERDEEXPERIENCE.CO.UK

26 As fotografias de crianças são muito frequentes nas representações iconográficas. Como afirmam Pritchard \& Morgan, existe "[...] a tradição dos postais ilustrados de apresentar as populações indígenas como crianças ou como 'anciãos', as primeiras inocentes e os segundos sábios - e ambos dificilmente susceptíveis de desafiar e causar desconforto ao olhar turístico" (2003: 123-124). 
Figura 5: Cultura e Património - População e Costumes - faina e pescadores

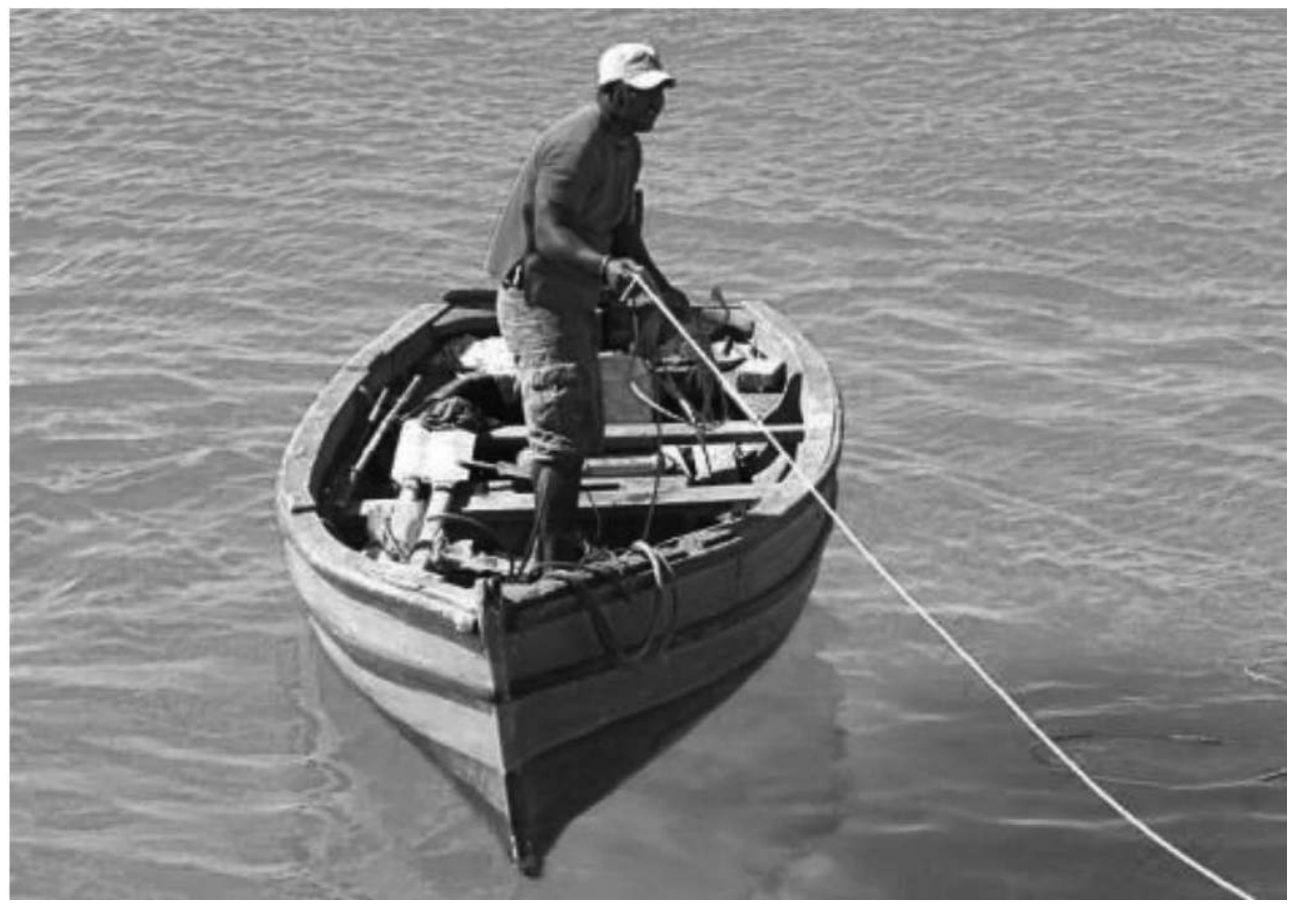

FONTE: WWW.CAPEVERDEEXPERIENCE.CO.UK

Figura 6: Cultura e Património - População e Costumes - transporte de água (crianças)

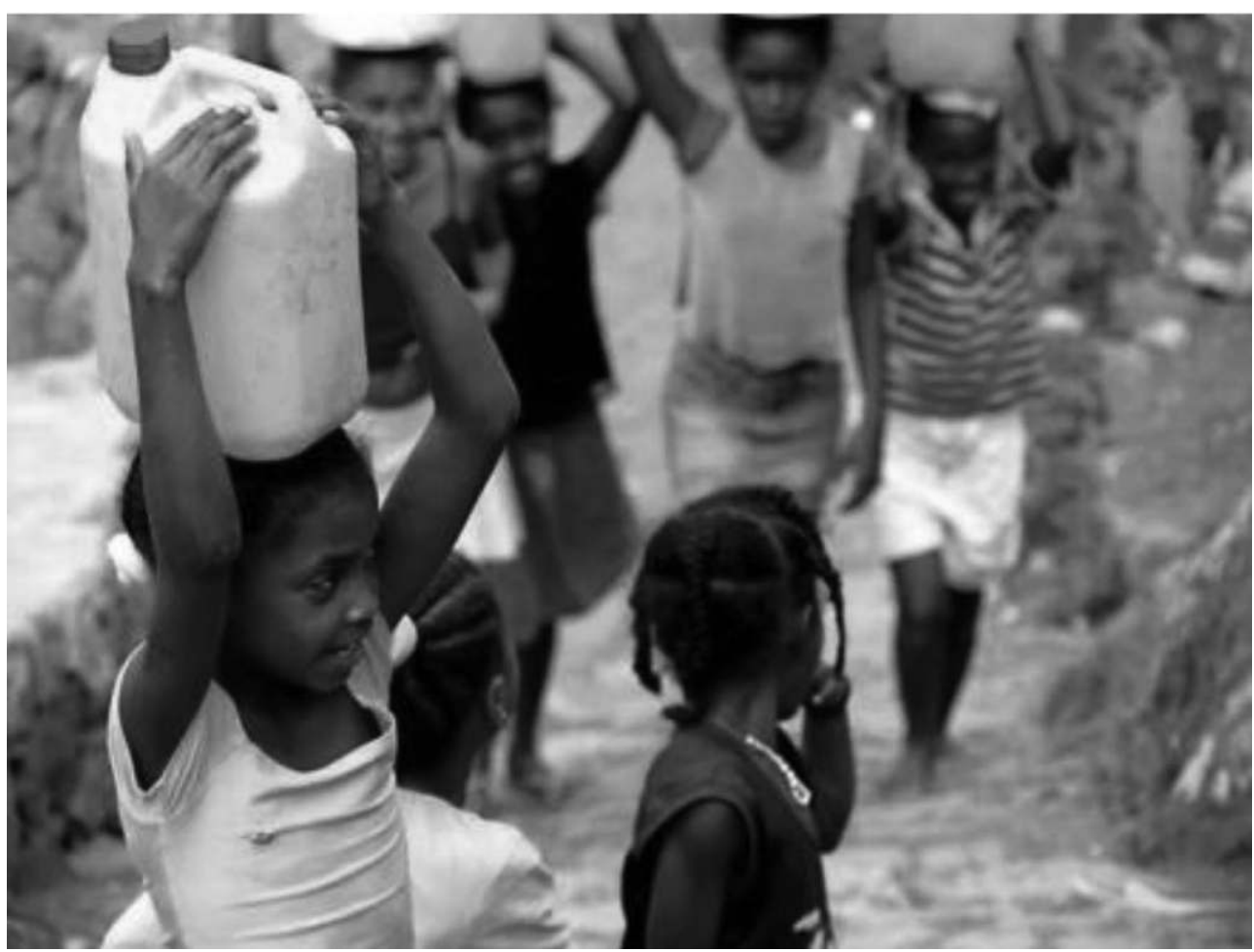

FONTE: WWW.CAVOQUINHO.COM 
Figura 7: Cultura e Património - População e Costumes - transporte de água (burro)

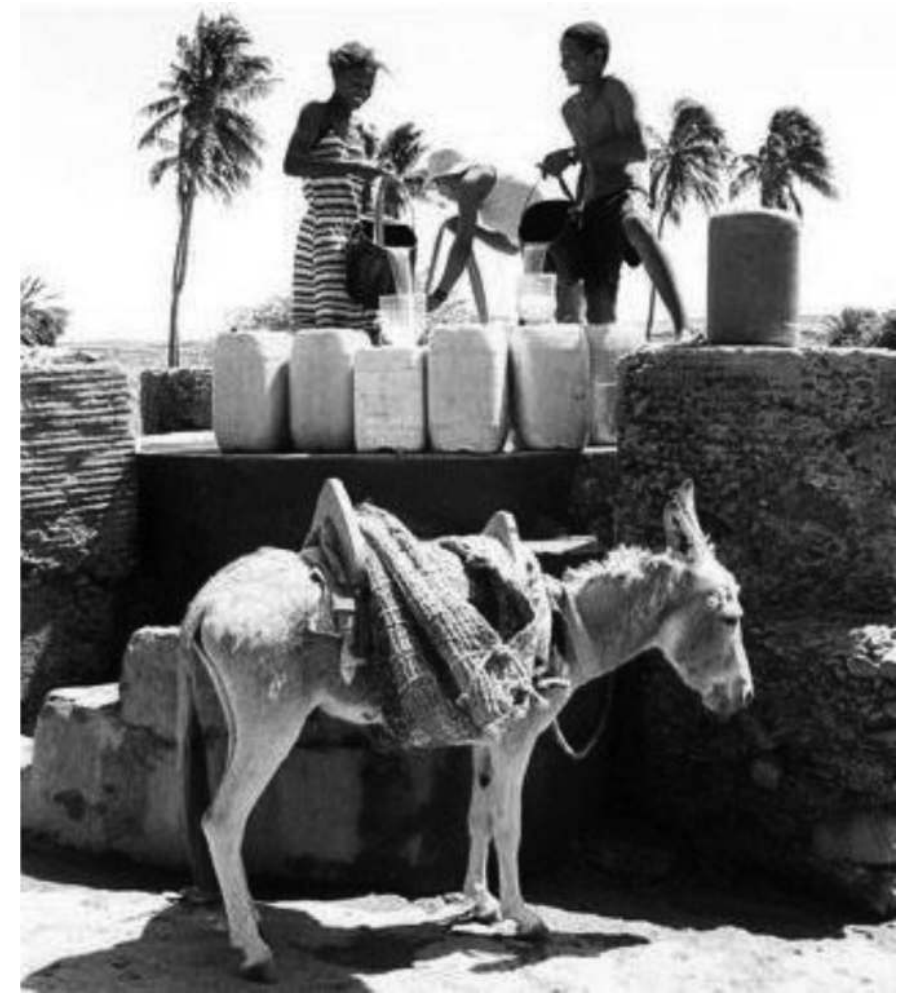

Fonte: www.orbitur.cv

Outros elementos, referentes ao quotidiano, têm também grande destaque. A faina dos pescadores é um dos mais recorrentes, mas outros, como o transporte de água, são também frequentemente apresentados.

No que respeita à "História", o passado colonial é muitas vezes descrito de forma quase condescendente, exortando tempos que, se para uns significaram o apogeu imperialista, para outros, sobretudo a população local, lembram um agrilhoamento físico e simbólico. De notar aqui os impactos turísticos que se esperam da recente ascensão em Junho de 2009 - da Cidade Velha ao estatuto de Património Mundial da Humanidade pela UNESCO. O processo de patrimonialização e os discursos a ele associados revelam, de modo inequívoco, o processo selectivo e de envernizamento social do discurso turístico promocional. Em termos iconográficos, as referências à História fazem-se fotografando estes lugares que evocam tempos longínquos.

Para além destas categorias, e no que respeita exclusivamente ao discurso narrativo, é possível identificar determinados códigos de apresentação como os recursos estilísticos (nomeadamente utilização de adjectivos), a prosa poética e o apelo às sensações, tão determinantes na formação e comunicação da imagem de um destino.

Como referimos, a imagem turística não é apenas a forma como o destino é representado em termos pictóricos e decorre também da experiência do visitante in loco (ou da sua antecipação), devendo evocar um sentimento significativo. Neste sentido, o design turístico confronta-se com questões não só de apresentação mas de conteúdo. Assim, é imperativo que a promoção turística conceba e transmita um todo experiencial coerente (Sternberg, 1997). Esta faceta experiencial da actividade turística impõe que se adopte uma perspectiva que vai além daquilo que se vê, interpretando a paisagem como 
um fenómeno simultaneamente visual e experiencial, na medida em que um destino turístico é experienciado não só através da visão mas dos outros sentidos (Tuohino \& Pitkänen, 2004). Assim, o discurso turístico apela também às sensações dos visitantes.

“[...] é impossível [...] assistir ao pôr-do-sol [...] sem ficar emocionado e sem respiração. É pouco provável que consiga percorrer o interior da ilha sem ficar estarrecido com a magnífica paisagem natural [...] Assim como também é difícil que percorra as dunas ondulantes [...] sem sentir a adrenalina do desconhecido por detrás de cada elevação. Fácil mesmo é que [...] surja um cocktail de emoções que convidam, não raras vezes, à meditação e à nostalgia" (Mourato, A., "Boa Vista, a ilha da morabeza", APAVT - Associação Portuguesa das Agências de Viagens e Turismo, n. ${ }^{\circ}$ 17, Janeiro/Fevereiro 2009, revista, p. 33)

31 Como vimos, a cor é outro elemento de extrema importância que se destaca particularmente nas fotografias, mas que é utilizado exaustivamente no texto. Dois exemplos:

"Mais à frente, outra paisagem quase indescritível. Misturado com o azul do céu, vimos o verde do mar, o dourado do areal, palmeiras e muito branco. 0 branco era das salinas [...]" (Caria, T., "Boavista 'nha cretcheu', A ilha mais bem guardada de Cabo Verde", Viajar, n. . 244, Dezembro 2008, revista, p. 12)

"[...] numa gradação de tons que vão desde o branco das salinas, ao negro vulcânico, passando pelo ocre da terra barrenta e pelos verdes que de vez em quando pontuam a paisagem." (Mourato, A., "Boa Vista, a ilha da morabeza", APAVT - Associação Portuguesa das Agências de Viagens e Turismo, n.․ 17, Janeiro/Fevereiro 2009, revista, p. 33)

Nesta análise da promoção turística de Cabo Verde foi também possível identificar aquilo que denominámos de "Imagens emblemáticas" gerais e particulares. As primeiras referem-se às apresentações que, sendo tão recorrentes, acabam por tornarse clichés descritivos ou ilustrativos de Cabo Verde como um todo. As segundas dizem respeito às imagens (textuais e visuais) que estão, também recorrentemente, associadas a lugares específicos e deles se tornam emblemáticas, na medida em que a cada ilha correspondem atractivos particulares.

No que concerne as "Imagens emblemáticas gerais", no discurso narrativo distinguemse cinco elementos recorrentes na descrição de Cabo Verde enquanto destino turístico: tropical, exótico, paraíso, pitoresco e África. Vejamos alguns exemplos:

"A sua beleza paisagística faz desta ilha um paraíso para os turistas que procuram, ao mesmo tempo, um ambiente tropical e a tranquilidade de um lugar pouco explorado e bucólico." (Soltrópico, Cabo Verde, Ilhas da Morabeza, s/d., brochura, p. 13 e Soltrópico, Cabo Verde, Verão 2009, brochura, p. 31, www.soltropico.pt)

"Longe do barulho e da confusão, vá à descoberta deste arquipélago, um paraíso perdido. Quando chegamos, os sentidos deslumbram-se! Que cores, que cheiros, que sons! 'Perdemos' horas no mercado da Assomada... A passear nos estreitos corredores, a adivinhar alguns dos produtos que se vendiam, a tentar entender o que as vendedoras diziam, a tropeçar na criançada que fazia do chão o seu pátio dos sonhos, a sorrir de contentamento sob o brilho do sol [...] a regatear, a comprar panos e doces de coco... Isto sim, é África 'pura'!" (Anónimo, “O país da 'morabeza”, Cabo Verde, o país da "morabeza", 2005, separata da revista Viajar, p. 6)

No que respeita exclusivamente à representação iconográfica existem outras "Imagens emblemáticas gerais" que são recorrentemente utilizadas: o pôr-do-sol e os botes de pesca ocupam grande parte do estímulo visual utilizado na promoção turística de Cabo Verde. 

e visual, estas acompanham a heterogeneidade turística do arquipélago, coincidindo cada descrição com traços característicos de cada ilha. Assim, quanto à ilha do Fogo, é sempre mencionada e fotografada a imponência e beleza do vulcão e a aridez negra de onde brota vida (vinho e café), bem como a população de cabelos louros e olhos verdes (descendente de um exilado francês do século XIX), ainda que esta esteja concentrada numa pequena zona da ilha. São também imagem de marca a arquitectura colonial dos sobrados senhoriais. Em Santo Antão, a "ilha verde", mencionam-se e fotografam-se as montanhas e os vales, as ribeiras e as vertiginosas ribanceiras, mas também a produção artesanal de grogue. Estas representações selectivas ignoram toda a metade árida do Sul da ilha. Em Santiago, a ilha "mais africana", sublinha-se o potencial variado, das praias às zonas montanhosas, assim como a história colonial, com os devidos destaques para a Cidade Velha e o Tarrafal. Relativamente à ilha do Sal, predominam as descrições das praias com os seus magníficos areais, e as salinas. $\mathrm{Na}$ Boavista, as praias igualmente, mas também as dunas. Além disso, esta ilha é sempre definida como o berço da morna. São Vicente, a ilha da cultura e das artes, dos festivais de música, do Carnaval e da vida nocturna do Mindelo cosmopolita.

Como vimos, os atractivos turísticos de Cabo Verde são variados e não se esgotam no produto "sol e mar". Outros recursos, como a história e a cultura, são capitalizados pelo turismo, sendo alvo de uma atribuição de significado simbólico enformadora de representações turísticas e identitárias. E além de um clima convidativo ou do apelo de um mar e areal "paradisíacos", existem outros traços paisagísticos bem diferentes que são também parte integrante da comercialização turística e promotores de outros tipos de turismo que não o balnear. Esta descentralização imagética que caracteriza a promoção turística de Cabo Verde não é apenas consequência da diversidade orográfica e paisagística do arquipélago. Revela também uma estratégia de afirmação de um destino turístico plural, de forma a contrariar o esgotamento de um modelo baseado no "sol e mar".

Sendo o turismo tomado como uma alavanca do desenvolvimento económico do país, importa apelar a um público amplo e diversificado que veja no arquipélago um destino apelativo. Para tal, são mobilizados esforços no sentido de transformar o país num produto turístico sedutor, suficientemente forte no mercado turístico internacional. Sendo a imagem turística tantas vezes o primeiro contacto que os turistas têm com um destino, não é difícil perceber a vontade, partilhada por políticos e empresários, de criar uma imagem de marca para Cabo Verde que reflicta a unidade na diversidade. A simbologia desta imagem passará inevitavelmente por alguns dos elementos e atributos que referimos aqui.

\section{Reflexões finais}

Objecto de estudo estigmatizado no seio das Ciências Sociais, o turismo é um tema constantemente relegado para segundo plano, considerado ainda, por muitos, como um assunto pouco sério, ou sequer digno de estudo. 0 turismo parece não merecer o devido destaque na agenda académica por se tratar, aparentemente, de uma prática social vazia, irremediável e negativamente conotada com o lazer, o ócio e o hedonismo. Adicionalmente, o turismo é também encarado como o responsável por muitas

Forum Sociológico, 18 | 2008 
desigualdades económicas e sociais e como o deturpador cultural por excelência. Neste sentido, e como alerta Amirou:

[...] posicionar o turismo como objecto de estudo consiste portanto em evitar esta malha de juízos de valor. [...] o turismo é assim responsabilizado por disfuncionamentos que lhe são muito anteriores, dos quais ele não é mais do que um dos reveladores. [...] para reflectirmos sobre o turismo devemos, antes de mais, libertá-lo da sua carga ideológica, moral e comercial, a fim de o tornar simplesmente um objecto de conhecimento (2007: 23, 25, itálico do autor).

o turismo encerra em si uma panóplia imensa de questões, funcionando como uma espécie de barómetro da realidade social. Pelo facto de espelhar questões centrais dos debates teóricos da contemporaneidade, o turismo constitui-se como uma lente privilegiada de análise do universo social. 0 estudo dos impactos (económicos, sociais, ambientais e culturais) do turismo na sociedade abre-nos um horizonte de possibilidades que nos permite não só pensar sobre comportamentos lúdicos, consumo, alteridade e identidade cultural, como nos possibilita reflectir sobre mecanismos de produção de significado.

40 Ao estudarmos o fenómeno turístico importa estarmos atentos às relações de poder entre hóspedes e anfitriões. O discurso promocional é, aliás, uma forma de representação que materializa, mesmo que subliminarmente, as assimetrias entre visitantes e visitados. A linguagem turística veicula representações de lugares e identidades culturais que são construídas num contexto desigual, e muitas vezes ambivalente, de hegemonia política e económica. É neste campo de forças que encontramos a marginalidade enquanto mercadoria turística (Azarya, 2004). Assim, as desigualdades de poder e legitimidade representacional repercutem-se no turismo, trazendo a lume sentidos de centro e periferia e estimulando um debate mais amplo sobre o posicionamento dos actores na hierarquia social e sobre as apropriações de capital simbólico que estão presentes no fenómeno turístico.

41 Como vimos, são muitas as imagens estereotipadas e as expressões valorativas que presidem o discurso da promoção turística, com o objectivo de direccionar o olhar para os aspectos considerados mais significativos. Há portanto que difundir imagens belas e vendáveis e deitar fora tudo o que obstrua a vista. Esta selecção cuidada dos conteúdos a transmitir demonstra claramente que o turismo é um fenómeno de consumo, mas também de produção. Assim, as imagens turísticas são representações que espelham os contextos de produção e consumo, muito mais do que reflectem a realidade dos destinos retratados (Bruner, 1989; Conceição, 1998).

Ao enfatizarem determinadas características do destino, as imagens turísticas omitem parte da realidade, por esta não ser concordante com a ideia de paraíso que a promoção turística pretende divulgar. E é neste sentido que é justificadamente argumentável que a linguagem publicitária envolve um processo complexo de (re)construção social da realidade (Conceição, 1998).

Mas se é certo que o modo como os destinos são apresentados junto do público define implicitamente as estratégias válidas de consumo, indicando o modo de observar e interpretar a realidade dos locais visitados, importa também problematizar algumas correntes de interpretação que tomam os turistas como meros agentes passivos. 0 turismo, enquanto experiência mediada, pode ser facilmente conotado com uma armadilha de marketing ou um logro publicitário a que qualquer turista sucumbiria acriticamente, negando-se assim a sua agência reflexiva. Contudo, devemos levar em 
linha de conta que as representações turísticas que estas imagens enformam são múltiplas e apropriadas distintamente pelos actores sociais.

A imagem turística de Cabo Verde, da qual aqui deixámos alguns fragmentos descritivos e ilustrativos, não se compadece com uma leitura meramente lúdica e floreada de lugares e pessoas. Os conteúdos simbólicos veiculados através do texto escrito ou das imagens captadas nas objectivas remetem-nos para uma visão paradisíaca do arquipélago de Cabo Verde. A compressão e selecção da realidade, próprias da linguagem promocional, revelam-se aqui, uma vez mais, como moldes de atribuição de significado que permitem situar e assinalar o arquipélago no vastíssimo leque de destinos propícios a uma experiência extraordinária.

Como vimos, a exotização do Outro surge como uma das características mais insistentes na actividade turística, que se ancora na diferenciação para desencadear práticas de lazer. Esta exotização compreende uma variedade de atributos ou conotações que, no seu todo, contribuem para inaugurar fronteiras entre um mundo conhecido e desinteressante e um mundo diferente, tantas vezes remoto, passível de ser descoberto e explorado. A mercadorização cultural da diferença encontra eco no discurso promocional. Assim, elementos como a hospitalidade da população, clima ameno, paisagens deslumbrantes, africanidade, tornam-se recursos manipuláveis pela promoção turística que, em conjunto, dão forma a representações sobre lugares e identidades culturais repletas de essencialismos. $O$ produto identitário que é exportado por via desta promoção é assim uma estilização de uma sociedade e de uma cultura que aparece aos nossos olhos como bem definida, delimitada e empacotada em papel de embrulho. Todavia, as sociedades, as culturas, e até a geografia dos espaços são mutantes, dinâmicas, compósitas e como tal não enclausuráveis nas imagens transmitidas textualmente ou iconograficamente através da linguagem turística.

Retomando a ideia da "diferença" - que degenera amiúde para uma "exotização" -, é interessante reflectir na forma como, apesar dela, a indústria turística se pauta por uma certa homogeneização de práticas e de imagens que anulam, de certa forma, a diferença, o particularismo, dos lugares e das culturas. Ou seja, Cabo Verde, na linguagem turística, impõe-se com determinados estandartes (praias paradisíacas, ambientes tropicais, culturas africanas, tradições ancestrais, etc.) passíveis de serem utilizados por muitos outros destinos e neste processo aquilo que está a ser usado como indicador de uma "diferença" acaba por diluir a especificidade de Cabo Verde. Mais ainda, estas categorias utilizadas são, na sua maioria, conceitos complexos, cuja densidade antropológica é abafada por uma simplificação de marketing que corresponde, não raras vezes, à forma pouco polida das representações sociais.

Por tudo o que aqui ficou exposto, julgamos ser possível confirmar o potencial analítico do turismo, cujos ângulos são, aliás, múltiplos e variados. Esta abordagem leva-nos a pensar o turismo como um fenómeno social amplo e complexo (o que extravasa em muito a perspectiva que o encara como um mera indústria ou actividade económica), a que urge dar redobrada atenção no campo das Ciências Sociais. 


\section{BIBLIOGRAFIA}

AMIROU, R. (2007), Imaginário turístico e sociabilidades de viagem, Estratégias Criativas, Associação Portuguesa de Turismologia.

ARORA, V. (2009), “Framing the image of Sikkim", Visual Studies, 24, pp. 54-64.

AURINDO, M. (2006), Portugal em cartaz: representações do destino turístico (1911-1986), Centro de Estudos Geográficos da Universidade de Lisboa.

AZARYA, V. (2004), “Globalization and international tourism in developing countries: marginality as a commercial commodity”, Current Sociology, 52 (6), pp. 949-967.

BRUNER, E. (1989), “Of Cannibals, Tourists, and Ethnographers”, Cultural Anthropology, 4 (4), pp. 438-445.

COHEN, E. (1993), "The study of touristic images of native people: mitigating the stereotype of a ste-

reotype", in D. Pearce e R. Butler (eds.), Tourism Research: critiques and challenges, London, Routledge, pp. 36-69.

COHEN, E. (1979), “A Phenomenology of Tourist Experiences”, Sociology, 13, pp. 179-201.

CONCEIÇÃO, C. (1998), "Promoção turística e (re)construção social da realidade", Sociologia Problemas e Práticas, 28, pp. 67-89.

CORDEIRO, M. (2009), “Em busca de um 'tempo parado': mobilidades e espaços turísticos na era da 'viagem instantânea' ", in R. do Carmo e J. Simões (orgs.), A Produção das Mobilidades: redes, espacialidades e trajectos, Lisboa, Imprensa de Ciências Sociais, pp. 113-135.

CRICK, M. (1989), "Representations of International Tourism in the Social Sciences: Sun, Sex, Sights, Savings, and Servility”, Annual Review of Anthropology, 18, pp. 307-344.

ECHTNER, C. e P. Prasad (2003), “The context of Third World tourism marketing”, Annals of Tourism Research, 30 (3), pp. 660-682.

ECHTNER, C. (2002), “The content of Third World tourism marketing: a 4A approach”, International Journal of Tourism Research, 4, pp. 413-434.

GARROD, B. (2008), "Exploring perception, a photo-based analysis", Annals of Tourism Research, 35 (2), pp. 381-401.

JENKINS, O. (2003), "Photography and travel brochures: the circle of representation", Tourism Geographies, 5, pp. 305-328.

MACCANNELL, D. (1989 [1976]), The Tourist - A New Theory of the Leisure Class, New York, Schocken Books.

MARKWICK, M. (2001), "Postcards from Malta - Image, Consumption, Context”, Annals of Tourism Research, 28 (2), pp. 417-438.

NASH, D. et al. (1981), “Tourism as an Anthropological Subject" [and Comments and Reply], Current Anthropology, 22 (5), pp. 461-481.

PRITCHARD, A. e N. Morgan (2003), “Mythic Geographies of Representation and Identity: Contemporary Postcards of Wales", Tourism and Cultural Change, 1 (2), pp. 111-130.

SHARPLEY, R. (2008 [1995]), Tourism, Tourists \& Society, Elm Publications. 
SMITH, V. (ed.) (1989 [1977]), Hosts and Guests - The Anthropology of Tourism, University of Pennsylvania Press.

STERNBERG, E. (1997), “The iconography of the tourism experience”, Annals of Tourism Research, 24 (4), pp. 951-969.

TUOHINO, A. e K. Pitkänen (2004), “The transformation of a neutral lake landscape into a meaningful experience - Interpreting tourist photos”, Journal of Tourism and Cultural Change, 2 (2), pp. 77-93.

URRY, J. (1990), The Tourist Gaze - leisure and travel in contemporary societies, London, Sage Publications.

\section{ANEXOS}

\section{Fontes publicitárias}

Anónimo, “O país da 'morabeza"”, Cabo Verde, o país da 'morabeza'”, 2005, separata da revista Viajar, p. 6.

Caria, T., "Boavista 'nha cretcheu', A ilha mais bem guardada de Cabo Verde", Viajar, n.o 244, Dezembro 2008, revista, pp. 10-13.

Mourato, A., "Boa Vista, a ilha da morabeza", APAVT - Associação Portuguesa das Agências de Viagens e Turismo, n.ํㅜ 17, Janeiro/Fevereiro 2009, revista, pp. 32-36.

Rolão, P., "Cabo Verde, terra morna”, Volta ao Mundo, n. 91, Maio 2002, revista, pp. 66-98.

Soltrópico, Cabo Verde, Ilha da Boavista, 2008, brochura.

Soltrópico, Cabo Verde, Ilhas da Morabeza, s/d., brochura.

Soltrópico, Cabo Verde, Verão 2008, brochura.

www.capeverdeexperience.co.uk

$\underline{\text { www.cavoquinho.com }}$

www.orbitur.cv

www.soltropico.pt

\section{NOTAS}

1. Este artigo baseia-se na dissertação de Mestrado em Antropologia Social e Cultural realizada pela autora no Instituto de Ciências Sociais da Universidade de Lisboa.

2. Não obstante, estas conotações aplicam-se também a locais relativamente próximos, como demonstra Maria João Cordeiro (2009) na sua análise sobre a representação turística de Portugal em guias de viagem e artigos de imprensa alemães. Esta transversalidade denota um dado importante a ter em conta sobre a promoção turística, cujos conteúdos representacionais, tal como diz a autora, "[...] revelam-se monotonamente inalteráveis" (2009: 122). Como veremos mais à frente, as categorias e descrições que se aplicam a Portugal são coincidentes com muitas das que observámos para Cabo Verde.

3. Todas as citações de textos em língua estrangeira foram traduzidas pela autora. 
4. Esta secção tem por base uma análise, que realizámos no âmbito da tese de mestrado, dos discursos visuais e narrativos presentes na promoção turística de Cabo Verde, com o objectivo de descortinar a forma como o arquipélago é caracterizado e apresentado enquanto destino turístico. Para tal, recorremos a uma variedade de fontes de informação, desde guias turísticos e brochuras a imprensa e sites online. De sublinhar que estes diferentes suportes informativos têm finalidades distintas e por vezes públicos diferenciados. Porém, apresentam uma matriz discursiva idêntica. $O$ nosso propósito nesta análise era identificar os temas e os elementos presentes na promoção turística de Cabo Verde, focando a nossa atenção quer na terminologia utilizada no discurso narrativo, quer na iconografia apresentada no discurso visual.

\section{RESUMOS}

Partindo do contributo teórico e empírico de alguns autores, este artigo pretende estimular uma reflexão sobre os mecanismos subjacentes à construção da imagem turística de um destino que pressupõem um processo complexo de construção de representações sociais sobre determinados lugares e culturas. Com base numa análise do discurso promocional de Cabo Verde, procurámos desvendar a forma como este arquipélago é descrito enquanto destino turístico, revelando a diversidade de elementos presentes na imagem turística contemporânea de Cabo Verde. Assim, com base nos discursos visuais e narrativos presentes na promoção turística de Cabo Verde, pretendemos, por um lado, identificar as imagens que são produzidas e difundidas e que impulsionam a escolha deste destino e, por outro, situar o discurso da promoção turística num contexto mais alargado de criação e manipulação de significados simbólicos.

The purpose of this article is to stimulate a reflection about the mechanisms that underlie the construction of the touristic image of a travel destination, by analyzing theoretical and empirical contributions from several authors. These mechanisms presume a complex process of construction of social representations about particular places and cultures. By analysing the promotional discourse of Cape Verde, we sought to unravel how this archipelago is described as a tourist destination and to reveal the diversity of elements that build the contemporary touristic image of Cape Verde. From the visual and narrative discourses of the touristic promotion of Cape Verde, we sought, on one hand, to identify the images that are produced and propagated and that motivate the choice of this destination and, on the other hand, to place the touristic promotional discourse within a wider context of creation and manipulation of symbolic meanings.

\section{ÍNDICE}

Keywords: Cape Verde, tourism, destination image, promotional discourse

Palavras-chave: Cabo Verde, turismo, imagem de destino, discurso promocional 


\section{AUTOR}

\section{MARIA DO CARMO LORENA SANTOS}

Instituto de Ciências Sociais da Universidade de Lisboa

carmo.santos@ics.ul.pt 